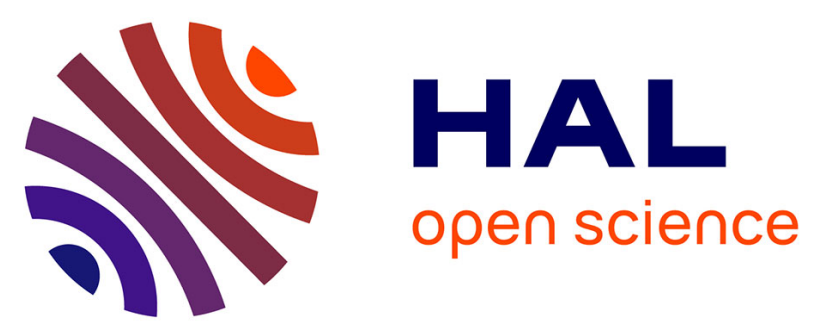

\title{
The effect of size on the strength of coarse rock aggregates and large rockfill samples through experimental data
}

Carlos Ovalle, Etienne Frossard, Christophe Dano, Wei Hu, Siegfried Maiolino, Pierre-Yves Hicher

\section{To cite this version:}

Carlos Ovalle, Etienne Frossard, Christophe Dano, Wei Hu, Siegfried Maiolino, et al.. The effect of size on the strength of coarse rock aggregates and large rockfill samples through experimental data. Acta Mechanica, 2014, 225 (8), pp.2199-2216. 10.1007/s00707-014-1127-z . hal-01501213

\section{HAL Id: hal-01501213 https://hal.science/hal-01501213}

Submitted on 4 Apr 2017

HAL is a multi-disciplinary open access archive for the deposit and dissemination of scientific research documents, whether they are published or not. The documents may come from teaching and research institutions in France or abroad, or from public or private research centers.
L'archive ouverte pluridisciplinaire HAL, est destinée au dépôt et à la diffusion de documents scientifiques de niveau recherche, publiés ou non, émanant des établissements d'enseignement et de recherche français ou étrangers, des laboratoires publics ou privés. 


\title{
Carlos Ovalle • Etienne Frossard • Christophe Dano • \\ Wei Hu • Siegfried Maiolino • Pierre-Yves Hicher \\ The effect of size on the strength of coarse rock aggregates and large rockfill samples through experimental data
}

\begin{abstract}
Testing the mechanical response of coarse granular materials requires very large and expensive laboratory equipments. During the 1960s, pioneering experimental programs were carried out on several rockfill dam materials, and those results are still a reference for engineers and researchers. However, only few experimental works have been reported to this day, and due to the scarcity of empirical data, the role of the size effect caused by grain crushing is not well known. To improve understanding of this rarely studied issue and the influence of individual particle strength, this paper analyzes the size effect on rock aggregate crushing strength and its connection with the shear envelope of rockfills. The suitability of the 4-parameter Weibull equation to describe size effects on the crushing strength reported in the literature is discussed. Furthermore, a Weibull statistical analysis was carried out for a wide number of experimental results on rock aggregates, where it has been observed that strength decreases with particle size. In parallel, the results of large triaxial tests on homothetic scaled rockfill samples of 250 and $1,000 \mathrm{~mm}$ in diameter reveal that the coarser the material, the higher the amount of grain breakage and the lower the shear strength. The impact of size effects obtained from the experiments is analyzed and discussed in terms of the factor of safety of rockfill slope stability. Furthermore, the results are compared with the only existing theoretical method that links the rock aggregate with the strength of the granular assembly. Good agreement between the empirical results and this theoretical method has been confirmed.
\end{abstract}

C. Ovalle · C. Dano $(\varangle) \cdot$ P.-Y. Hicher

Ecole Centrale Nantes, CNRS UM 6183, LUNAM University, 1 rue de la Noë, BP 92101,

44321 Nantes Cedex 3, France

E-mail: christophe.dano@ec-nantes.fr

C. Ovalle

Department of Structural and Geotechnical Engineering,

Pontificia Universidad Católica de Chile, Santiago, Chile

E-mail: covalle@ing.puc.cl

E. Frossard

Tractebel Engineering - Coyne et Bellier, Gennevilliers, France

W. $\mathrm{Hu}$

State Key Laboratory of Geohazard Prevention and Geoenvironment Protection,

Chengdu University of Technology, Chengdu, China

S. Maiolino

CETE de Lyon, Lyon, France 


\section{Introduction}

The subject of the size effect on brittle material strength is in itself not new, it has been experimentally treated in the past, and it is well known that strength is inversely proportional to sample size. A physical explanation was given by Griffith [15], who stated that brittle failure occurs through the crack opening at the tip of internal flaws, or discontinuities, in the solid material. Therefore, the probability of finding these flaws within a specimen increases with its size, which results in a decrease in the strength. Afterward, based on the weakest link concept (WLC), Weibull [38] proposed a statistical distribution for strength as a function of specimen size, which can predict the size effect through the data scatter of experimental results. The comprehension of the phenomenon of the size effect is essential in order to predict the mechanical behavior of a prototype when one characterizes the problem by means of tests on small-scaled samples in the laboratory.

The size effect plays a role in brittle sand grain and rock aggregate crushing strength $[1,28,29]$. As a consequence, crushable granular materials composed by brittle grains also present an effect of particle size. For instance, Marachi et al. [24] have shown that for a given shearing condition, the coarser the granular material is, the higher the grain breakage ratio, the higher the volumetric contraction and the lower the peak friction angle will be. For coarse granular materials commonly used in civil engineering, such as rockfills, this phenomenon presents difficult experimental problems because samples formed by large rock particles (i.e., $200 \mathrm{~mm}$ in diameter or more) cannot be tested inside shear or oedometric devices in the laboratory. However, small-scaled samples of around $1,000 \mathrm{~mm}$ in diameter with maximal particle size $\left(d_{\max }\right)$ of around $100-200 \mathrm{~mm}$ have been tested with very large triaxial devices $[2,5,17,24-26,33,36]$. Nevertheless, due to the high cost of such large tests, not much experimental data are available and only few authors have so far also tested the rock aggregate strength [17,26], which is the origin of crushing and size effect. Extending the work of McDowell and Bolton [29] on the micro-mechanics of particle breakage, Frossard [12] treated theoretically the problem of the size effect in granular materials. This method predicts the size effect on the rockfill shear strength with nonlinear envelope, based on a statistical representation of rock aggregates crushing strength and assuming that the same amount of particle breakage of scaled materials is obtained at different shear stress magnitudes, which will allow the aggregate strength to be linked with the shear envelope.

The aim of this paper is to contribute to the discussion on the phenomenon of size effect and the connection between the breakage mechanics of individual particles and the granular packing, supported by new data on two rockfills. The impact of size effects obtained from the experiments is analyzed in terms of the factor of safety (FS) of rockfill slope stability. In addition, the experimental results validate the multiscale method of Frossard, which was originally based on partial data from the literature.

\section{Size effects on rock aggregates strength}

\subsection{Empirical evidence}

Analogous to the tensile failure of a spherical particle under compression, the tensile strength (i.e., failure in mode I) of rock aggregates or sand grains can be indirectly obtained by diametral compression between two stiff parallel platens [29]. According to Jaeger [18], the characteristic tensile stress induced within the particle may be defined as

$$
\sigma=\frac{f}{d^{2}}
$$

where $d$ is the characteristic size of the particle and $f$ is the diametral compression force. Therefore, using Eq. (1), the tensile strength $\sigma_{f}$ can be obtained from the crushing force $f_{f}$. Following Lee [19], a power law expressing the size effect on $\sigma_{f}$ can be obtained (where $\alpha$ is an empirical parameter):

$$
\sigma_{f} \propto d^{\alpha} .
$$

Typical values of $\alpha$ are negative, indicating that the larger the particle size, the lower the tensile strength. For instance, Lee [19] reported $\alpha$ values of $-0.357,-0.343$ and -0.420 for Leighton Buzzard sand, oolitic limestone and carboniferous limestone, respectively, using grains from $d=1$ to $50 \mathrm{~mm}$. Similarly, using crushing tests on rock aggregates of $d=20$ to $80 \mathrm{~mm}$ reported by Marsal [26], $\alpha$ values are given by -0.43 , $-0.83,-0.59$ and -0.26 , for Pinzadaran gravel, El Infiernillo diorite, San Francisco basalt and Mica granitic gneiss, respectively. 
Table 1 Weibull modulus of soils grains and rock aggregates reported in the literature

\begin{tabular}{lll}
\hline Author(s) & Material & $m$ \\
\hline Nakata et al. [31] & Quartz sand & 4.20 \\
& Feldspar sand & 1.80 \\
Nakata et al. [32] & Silica sand & $1.82-3.04$ \\
& Toyura sand & 2.17 \\
& Aio sand & 1.93 \\
& Masado sand & 1.23 \\
McDowell [27] & Leighton Buzzard silica sand & $2.34-3.44$ \\
Lim et al. [20] & Ballasts (granodiorites, granite, porphyritic felsite) & $2.06-3.42$ \\
McDowell and Amon [28] & Quiou limestone sand & $1.16-1.93$ \\
Lobo-Guerrero and Vallejo [22] & Biotite gneiss & 2.75 \\
& Gray quartzite & 4.23 \\
\hline
\end{tabular}

\subsection{Weibull's theory on rock aggregates}

The statistical theory of the strength of materials proposed by Weibull [38] gives the following distribution for the survival probability of a material of size $d$ subjected to a tensile stress $\sigma$ :

$$
P_{S}(d)=\exp \left(-\left(\frac{d}{d_{o}}\right)^{n_{d}} \cdot\left(\frac{\sigma}{\sigma_{o}}\right)^{m}\right)
$$

where $\sigma_{o}$ is the characteristic strength $\left(P_{s}=37 \%\right.$ for a sample of size $\left.d_{o}\right)$ and $m$ controls the amplitude of data scatter on crushing strength. Equation (3) is based on the WLC, which is supported by the notion that, for a chain of length $d$ to survive under uniaxial stress, every element of length $d_{o}$ must also survive. The term $\left(d / d_{o}\right)^{n_{d}}$ is the scale ratio indicating how many links form the chain. According to Bažant and Planas [3], $n_{d}$ is the geometric similarity of the mechanical problem: $n_{d}=1,2$ or 3 , for linear, surface or volume similarity, respectively. For a given survival probability and known empirical parameters, a size effect relation is obtained between the induced tensile stress at failure $\left(\sigma_{f}\right)$ and the characteristic size of the sample $(d)$ :

$$
\sigma_{f} \propto d^{-n_{d} / m} .
$$

Empirical validation of Weibull's theory is possible by verifying the validity of the relation $\alpha=-n_{d} / m$ (from Eqs. (2) and (4)). For soil particles and rock aggregates under compression between two stiff parallel platens and assuming an isotropic homogeneous material, it has been generally assumed that failure occurs under bulk induced tensile stress, which gives $n_{d}=3$ [22,27-29].

Table 1 shows $m$ values for different materials reported in the literature. It can be seen that higher $m$ values of around 3 to 4 correspond to sound heterogeneous materials such as quartz sands, biotite and ballast. On the other hand, for feldspars, limestones and carbonates, $m$ varies between 1 and 3. McDowell and Amon [28] tested the application of Weibull's theory on weak limestone sand grains of similar geometry (i.e., rather spherical shape) by checking the ability of Eq. (4) for $n_{d}=3$ and obtained a very good agreement. McDowell [27] showed similar conclusions for silica sand and also Lobo-Guerrero and Vallejo [22] for rock fragments of biotite gneiss and gray quartzite.

However, tensile failure of rock samples or soil grains does not occur always under bulk induced stress. For instance, Ratigan [34] proposed geometric similarities of $n_{d}=2$ to represent size effects in granite disks after Brazilian tests, where failure was generally induced in weak surface flaws. Moreover, other authors have reported that Weibull's theory cannot always fit the empirical size effect on soil grains. For instance, Lim et al. [20] tested a number of railway ballast particles of $d=20$ to $50 \mathrm{~mm}$, and they did not found a good agreement between $\alpha$ and the theoretical exponent $-3 / \mathrm{m}$. They explained this fact arguing that the petrographic analysis showed an anisotropic heterogeneous material, so part of the hypotheses of Weibull's theory was unfulfilled. Based on analytical results of internal stress distributions in elastic spheres under diametral compression, Lim et al. [20] assumed that the maximum internal tensile stress could occur near the surface. In this case, and assuming the presence of surface flaws, they used a two-dimensional geometric similarity (i.e., $n_{d}=2$ ) and obtained a better agreement when comparing $\alpha$ to the exponent $-2 / m$. However, in this paper, it is shown that even an $n_{d}$ value smaller than 2 , say for instance $n_{d}=1$, gives a better fitting with the empirical results. Figure 1 presents the results of Lim et al. [20] on railway ballast particles for $\alpha$ and $-n_{d} / m$, and it is clear 


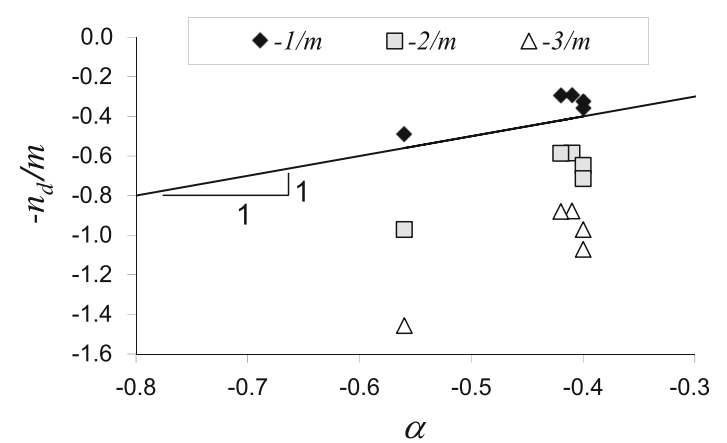

Fig. 1 Comparison of theoretical prediction of the size effect exponent with the empirical fitted value for different ballast materials (results from [20])

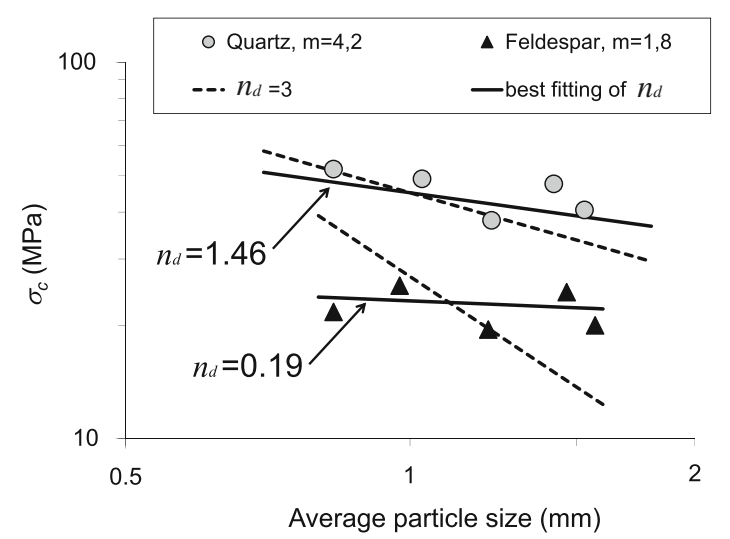

Fig. 2 Effect of particle size on crushing strength (results from [31])

that $n_{d}=1$ gives the closest solution for $\alpha=-n_{d} / m$, when compared to $n_{d}=2$ or 3 . However, as discussed later, this comparison may not be related to the physical sense of the WLC.

Nakata et al. [31] also reported an example of an unsuccessful prediction of size effects using Weibull's theory with statistics of compression tests on sand grains. They carried out crushing tests on quartz and feldspar sand grains of $d=0.84$ to $2.0 \mathrm{~mm}$. For a constant survival probability of $37 \%$, using Eq. (3) (with $n_{d}=3$ ), they obtained the theoretical size effect on the characteristic particle strength $\sigma_{c}$ as

$$
\sigma_{c}(d)=\left(\frac{d}{d_{o}}\right)^{-3 / m} \sigma_{o} .
$$

Figure 2 presents the comparison made by Nakata et al. [31] between $\sigma_{o}$ obtained by a Weibull statistical analysis and the prediction of Eq. (5). The authors noted that there was not a good agreement, particularly for the feldspar, presumably - they argued — because the flaw distribution may not have the geometric similarity assumed in Eq. (5).

On the other hand, in the absence of experimental data on rock aggregates' crushing strength to perform a statistical analysis, others authors have assumed that Weibull's theory is applicable for $n_{d}=3$. For instance, Frossard et al. [13] used published results of particle strength by Marsal [26] in order to fit the values of $m$ by using the relation $\alpha=-3 / m$ (where $\alpha$ is obtained from Eq. (2) for the average crushing particle strength shown in Fig. 10). Thus, the authors obtained values of $m$ from 4 to 15 on rock aggregates of El Infiernillo diorite and San Francisco basalt. Using the same approach, McDowell and Bolton [29] have indirectly estimated $m$ values between 5 and 10 in particle crushing tests performed by Lee [19] on oolitic limestone, carboniferous limestone and Leighton Buzzard sand. These values of $m$ obtained indirectly (i.e., not by a Weibull statistical analysis) seem to be too high in comparison with those reported in Table 1, and the results shown later in this paper for rock aggregates, probably because Weibull's theory is not always valid for $n_{d}=3$.

In general, if no information is available on material flaw distribution or internal stress distribution on particles, the physical sense of $n_{d}$ may be missed. As aforementioned, Weibull's theory assumed that the 
structure is equivalent to a uniaxially stressed bar, which can be extended to a three-dimensional analogy like a spherical particle under diametral compression. Afterward, if one considers an alternative structure with random geometry, all information about the mode of failure could be lost and become irrelevant [4]. This could be in the case of soil grains and rock aggregates with significant data scatter in particle shape. Moreover, if the material has a heterogeneous structure, the hypotheses of Weibull's theory are not satisfied; therefore, the physical sense of the WLC may be completely missed. As discussed before, this is probably the case in randomly shaped grains (e.g., high angularity) composed by nonhomogeneous or anisotropic materials, where one has no control of the internal stress distribution. Nevertheless, the Weibull distribution can still be a powerful statistical tool for practical applications. In this case, the parameter $n_{d}$ has to be fitted with the empirical results. For instance, in this work the best fittings of $n_{d}$ are obtained for the experimental results of Nakata el al. [31], which are presented in Fig. 2: $n_{d}=1.46$ and 0.19 for quartz and feldspar, respectively, following a purely phenomenological approach.

\subsection{Rock materials tested}

Experimental results on two kinds of rock aggregates were used in this work. Firstly, the results of Hu et al. [17] on a calcareous rock (CP) from a quarry located in Préfontaines, in the center of France, have been analyzed. Thin sections of CP rock samples shown in Fig. 3a reveal that the material is composed by micrite, that is to say, formed by consolidation of lime mud. The material is porous and presents traces of shell debris and bioturbation figures, as a result of reworking due to biological activity. As presented in Fig. 3b, CP rock aggregates are white and have a subangular shape, a structure characterized by an open porosity within the grains and a number of inclusions. Solid grains have a density of solids of $26.54 \mathrm{kN} / \mathrm{m}^{3}$, and the porosity of the rock is about $10 \%$, measured on cylindrical rock cores of $14 \mathrm{~mm}$ in diameter.

Secondly, rock aggregates from a quartzite shale rock (STV) from Trois Vallées quarry, in the north of France, have been tested. Figure 4a presents a picture of the material before the test, and it can be seen that particles are quite angular and flattened. The rock has an anisotropic sheeted structure with a clear main orientation, typically found in shale rocks. Figure $4 \mathrm{~b}$ presents electron microscope scans on fine fractions of crushed grain fragments sieved after a test. It appears clearly that the shale rock is composed by thin sheets. Once crushing occurs, a significant amount of fines is produced essentially by small pieces of detached sheets. The analysis of X-ray diffraction (XRD) scans of a fine fraction of the material (sieved under $0.08 \mathrm{~mm}$ ) shows that the powder is composed mainly of silica, with also significant amounts of aluminum and iron. The XRD measurement results show the presence of three main phases: $64 \%$ of quartz $\left(\mathrm{SiO}_{2}\right), 26 \%$ of albite $\left(\mathrm{NaAlSi}_{3} \mathrm{O}_{8}\right)$ and $10 \%$ of sodium aluminum silicate $\left(\mathrm{Na}_{6} \mathrm{Al}_{6} \mathrm{Si}_{10} \mathrm{O}_{32}\right)$. Solid grains have a density of solids of $27 \mathrm{kN} / \mathrm{m}^{3}$.

\subsection{Rock aggregates crushing tests}

$\mathrm{Hu}$ et al. [17] carried out a series of 144 rock aggregate crushing tests on CP rock aggregates, using a range of particle sizes from 7 to $80 \mathrm{~mm}$. Crushing tests were performed between two stiff parallel platens in a $10 \mathrm{kN}$ capacity device with a constant displacement rate of $0.1 \mathrm{~mm} / \mathrm{min}$. Particles were located over the fixed bottom plate and placed along its longer size in order to ensure stability. In this paper, these experimental data of particle crushing were separated by size fractions for a statistical analysis. Table 2 presents a summary of the analysis, where $d_{o}$ is the average size, and the induced tensile strength was computed according to Eq. (1) for $f_{f}$.

As proposed by Weibull [38], for a given size fraction (i.e., $d=d_{o}$ ), $m$ and $\sigma_{o}$ were obtained by writing Eq. (3) in the following form and fitting the best straight line between $\ln \left[\ln \left(1 / P_{s}\right)\right]$ and $\ln (\sigma)$ :

$$
\ln \left[\ln \left(\frac{1}{P_{S}}\right)\right]=m \cdot \ln \left(\frac{\sigma}{\sigma_{o}}\right) \text {. }
$$

Figure 5 presents the plottings of Eq. (6) for all tests of Hu et al. [17] on CP aggregates. Likewise, Fig. 6 shows that the results are in very good agreement with Weibull's distribution for an average value $m_{\text {avg }}=2.18$.

Similarly, 100 crushing tests were carried out on STV rock aggregates, using a range of particle sizes from 15 to $70 \mathrm{~mm}$. The same aforementioned statistical analysis was performed, and the results are shown in Table 2 and Figs. 7 and 8. A very good fitting with Weibull's distribution was also obtained with an average modulus $m_{\text {avg }}=1.54$. 

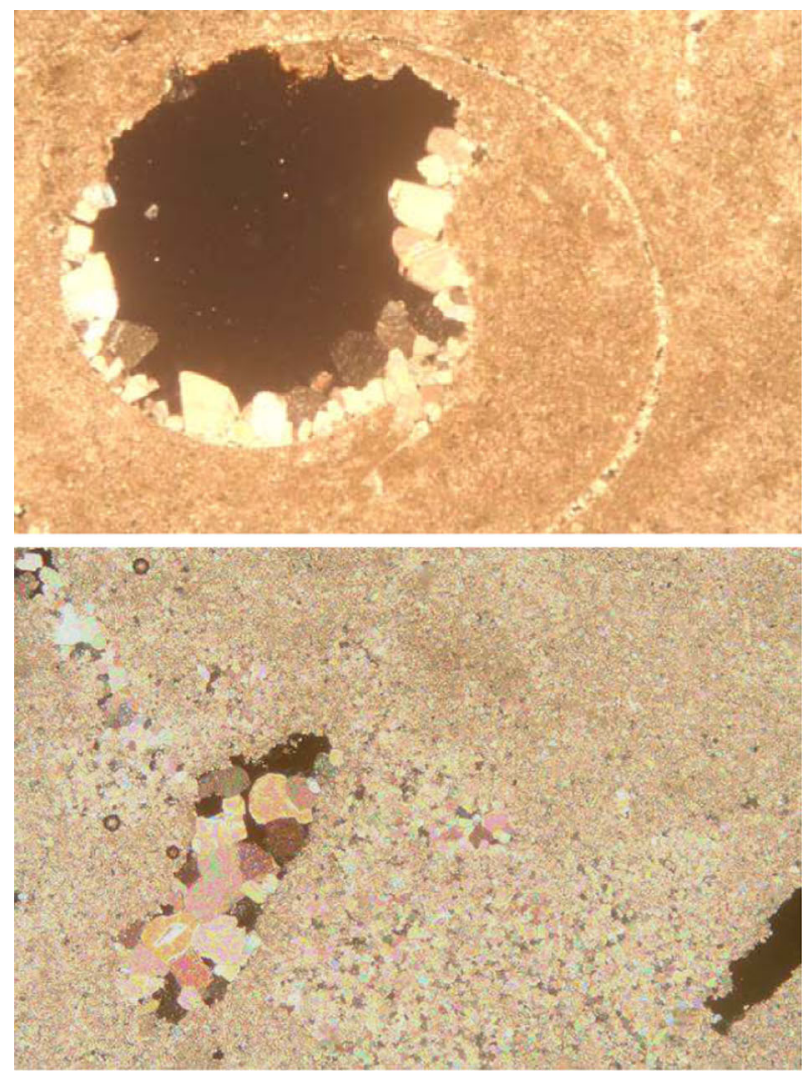

(a)

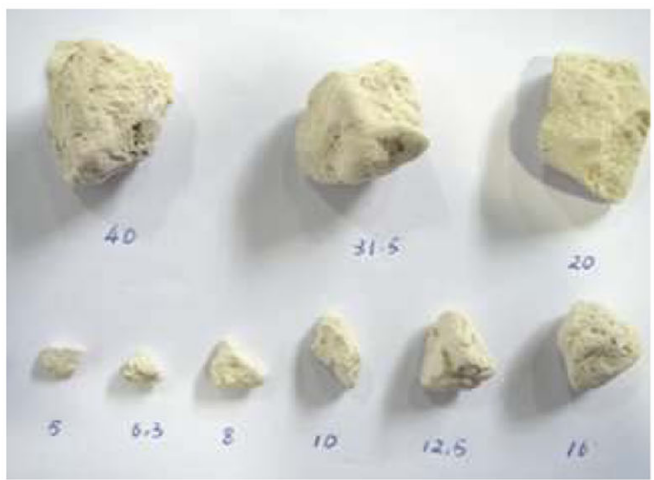

(b)

Fig. 3 CP rock samples: a microscopic observations on thin sheets, each image represents an area of about $5 \times 5 \mathrm{~mm}$, b rock aggregates of sizes 5 to $40 \mathrm{~mm}$

A clear size effect appears on particle strength for both CP and STV particles, and $m$ values are in the lower range of those reported in Table 1. Hence, data scatter is relatively high, presumably due to the random shape of subangular and angular grains. Figure 9 shows the crushing strength for all tests in CP and STV aggregates, as well as $\sigma_{o}$ for each size fraction. It can be seen that the size effect is stronger on STV in comparison with CP.

For $P_{s}=37 \%$ and given reference parameters $d_{o}$ and $\sigma_{o}$, Eq. (3) gives the following expression for the characteristic strength $\sigma_{c}$ as a function of $d$ :

$$
\sigma_{c}(d)=\left(\frac{d}{d_{o}}\right)^{-n_{d} / m} \sigma_{o}
$$




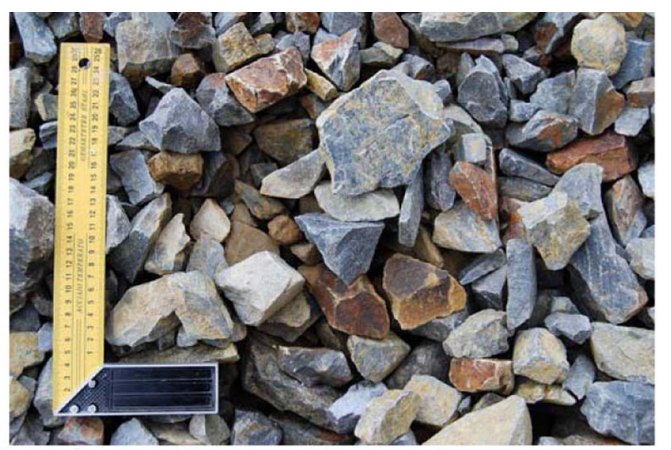

(a)

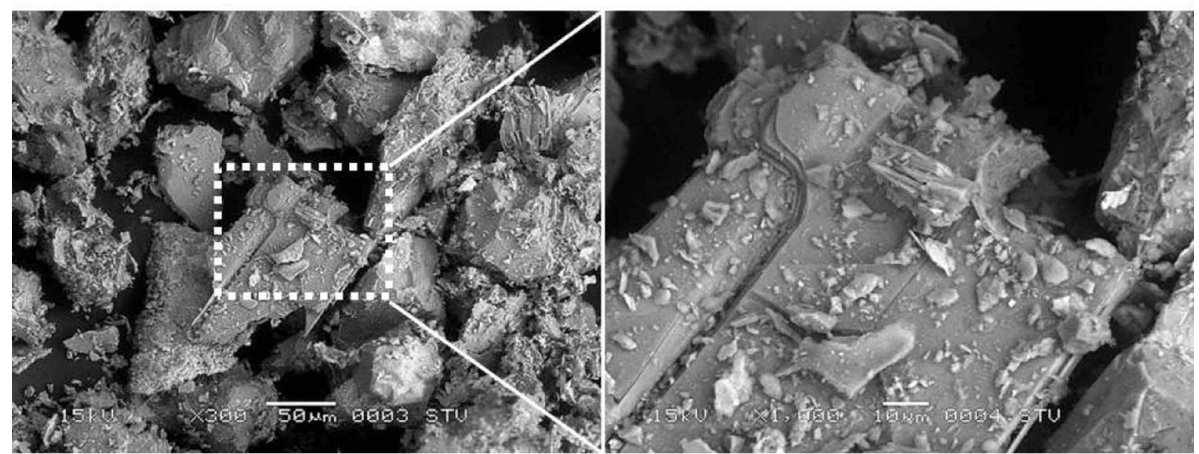

(b)

Fig. 4 STV rock samples: a angular rock aggregates of sizes 10 to $160 \mathrm{~mm}$, b microscopic observations on fine crushed grains sieved between 0.08 and $0.1 \mathrm{~mm}$

Table 2 Weibull statistical analysis of particle crushing tests by size fraction

\begin{tabular}{|c|c|c|c|c|}
\hline Size fraction $(\mathrm{mm})$ & No. of crushing tests & $d_{o}(\mathrm{~mm})$ & $m$ & $\sigma_{o}(\mathrm{MPa})$ \\
\hline \multicolumn{5}{|c|}{ Calcareous rockfill from Prefontaines $(\mathrm{CP})$} \\
\hline $7<\mathrm{d}<15$ & 41 & 10.9 & 1.55 & 3.35 \\
\hline $15<\mathrm{d}<25$ & 35 & 19.7 & 2.14 & 3.33 \\
\hline $25<\mathrm{d}<50$ & 41 & 44.6 & 2.51 & 2.68 \\
\hline $50<\mathrm{d}<80$ & 27 & 62.0 & 2.52 & 1.95 \\
\hline \multicolumn{5}{|c|}{ Quartzite shale rockfill from Trois Vallées (STV) } \\
\hline $15<\mathrm{d}<30$ & 37 & 25.4 & 1.53 & 16.99 \\
\hline $30<\mathrm{d}<40$ & 29 & 34.5 & 1.26 & 14.21 \\
\hline $40<\mathrm{d}<70$ & 34 & 48.4 & 1.82 & 12.16 \\
\hline
\end{tabular}

In order to obtain a prediction of the size effect using Eq. (7), it was assumed that the reference parameters for each rockfill are as follows: (i) the average value for Weibull's modulus $\left(m_{\text {avg }}\right)$ and (ii) the coarser size fraction as a reference for $d_{o}$ and $\sigma_{o}$. Figure 9 shows the fitting of Eq. (7) for both materials, with fitted $n_{d}$ of 0.63 and 0.81 for CP and STV, respectively. These results show that, as aforementioned, the geometric similarity represented by $n_{d}$ is far from the expected values (i.e., $n_{d}=2$ or 3 ), and the physical notion in Weibull's theory is no longer valid for the current heterogeneous and randomly shaped rock samples. Figure 10 presents the average particle crushing strength for each size fraction for CP, STV and four other materials used in rockfill dams and tested by Marsal [26] under similar conditions. It can be seen that CP and STV are in the lower and upper ranges, respectively, considering all aggregates.

\section{Size effects on the mechanical behavior of rockfills}

\subsection{Large triaxial tests}

For $\mathrm{CP}$ rockfills, Hu et al. [17] performed a series of drained triaxial tests on a dry material using two homothetic grain size distributions (GSD) with $d_{\max }=40$ and $160 \mathrm{~mm}$ and uniformity coefficient $C_{u}=d_{60} / d_{10}=2$ 

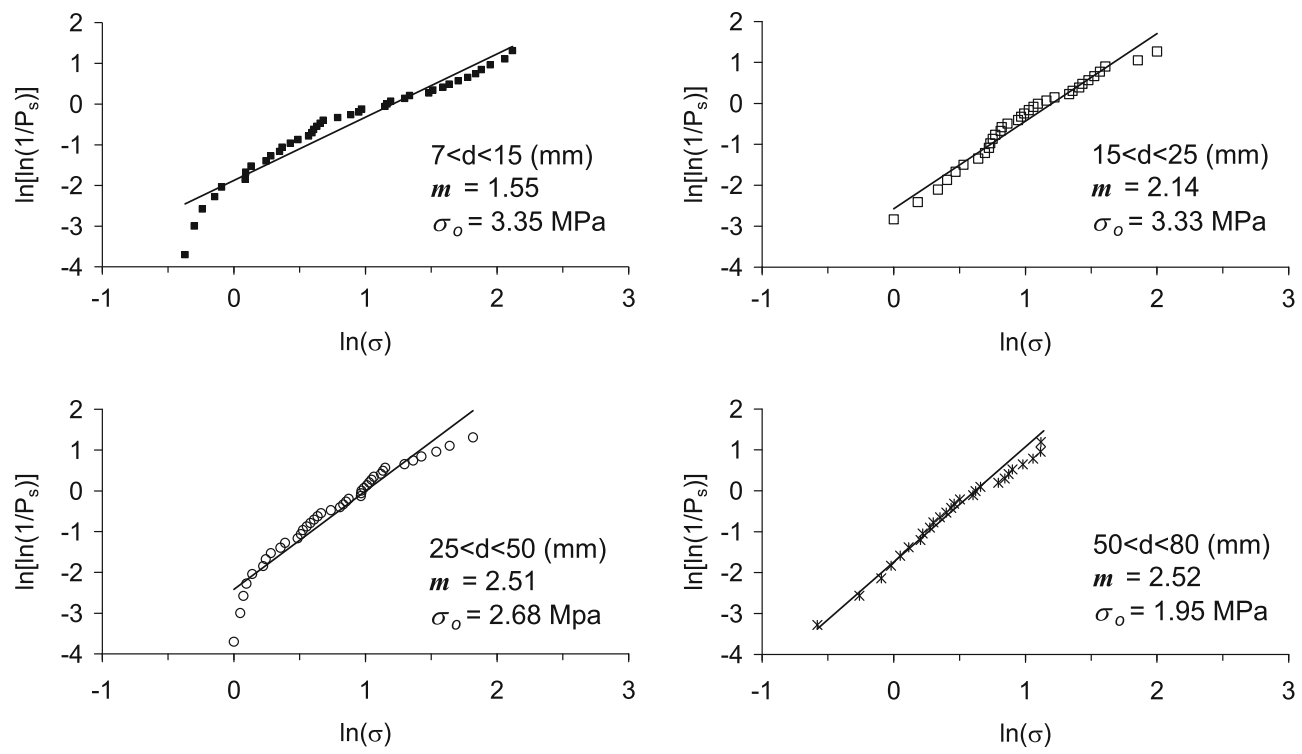

Fig. 5 Computation of Weibull parameters $m$ and $\sigma_{o}$ for $\mathrm{CP}$

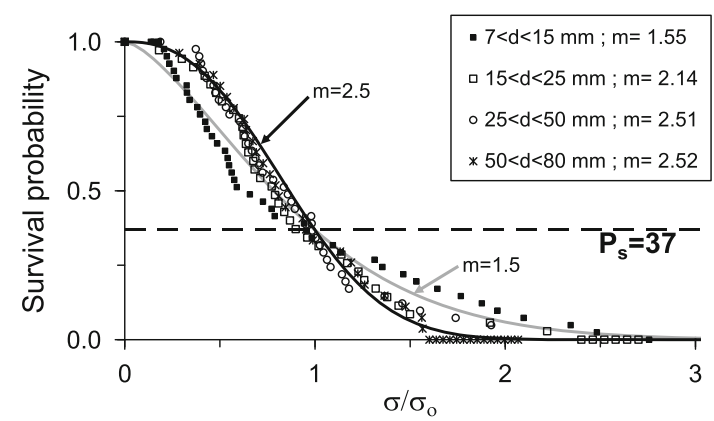

Fig. 6 Weibull distributions of CP rock aggregates
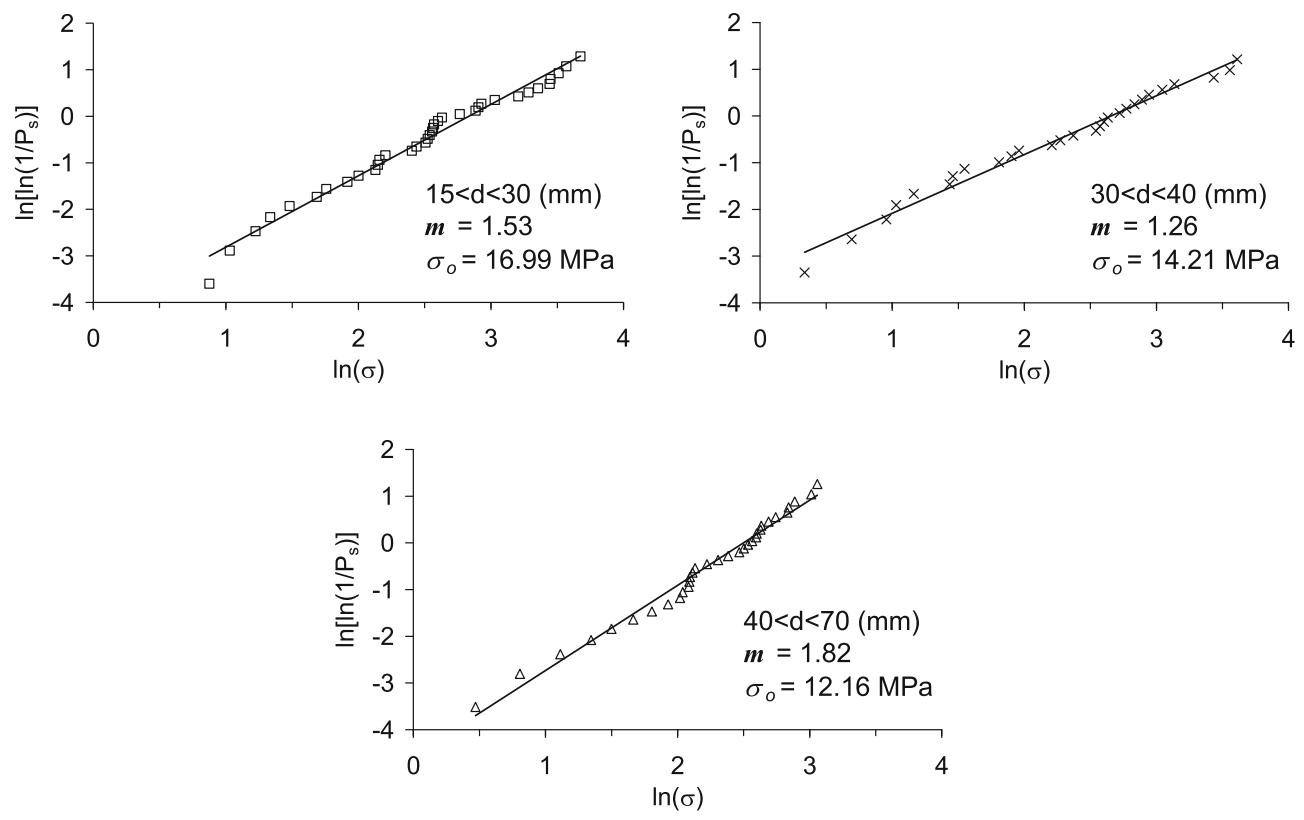

Fig. 7 Computation of Weibull parameters $m$ and $\sigma_{o}$ for STV 


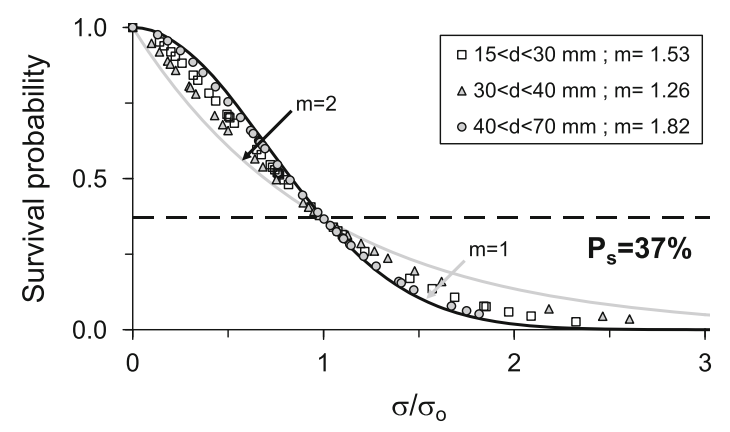

Fig. 8 Weibull distributions of STV rock aggregates

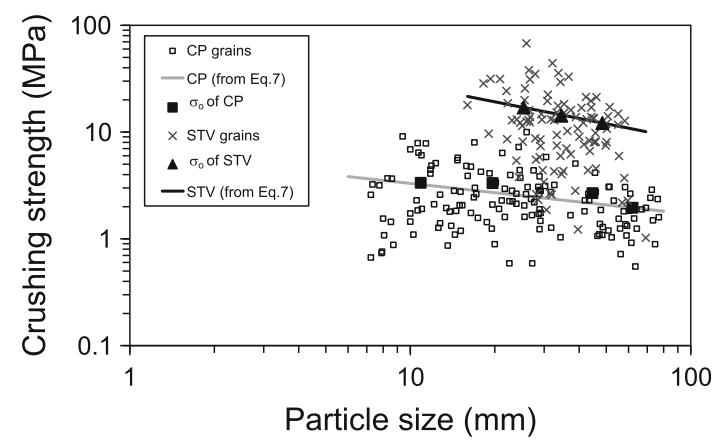

Fig. 9 Particles crushing strength and Weibull's theory predictions

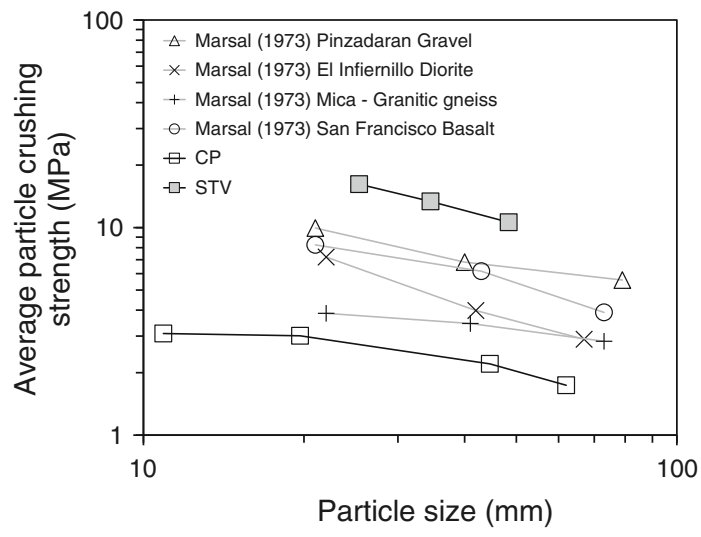

Fig. 10 Average particle crushing strength of rock aggregates

(see Fig. 11a) ( $d_{x}$ denotes the particle size for which $x \%$ are finer). A same series of triaxial tests were carried out on STV rockfills with $C_{u}=5$ (see Fig. 11b). Materials having $d_{\max }=40 \mathrm{~mm}$ are called CP1 and STV1, and those with $d_{\max }=160 \mathrm{~mm}$ are called CP2 and STV2. Table 3 presents all triaxial test conditions. It is assumed that particle shape and mineralogy are the same for two scaled materials of each rockfills because prior to sieving, each one was obtained from the same grinding process in the quarry.

Tests were run in two large triaxial devices, one for samples of $250 \mathrm{~mm}$ in diameter and $375 \mathrm{~mm}$ in height and the larger one for samples of $1,000 \mathrm{~mm}$ in diameter and $1,500 \mathrm{~mm}$ in height. Due to geometrical limitations in the large triaxial cell, the aspect ratio (height/diameter) of the samples tested in both triaxial cells is 1.5 , which is lower than the standard value of 2 . Even if under these conditions a nonhomogeneous stress distribution can be expected, both sample sizes present the same constraint, and it is assumed that the results are therefore comparable for size effects assessment. The volume change was measured by volume changes in the confining water. To allow this, the cylindrical envelope of the large triaxial cell $(1,000 \mathrm{~mm}$ samples $)$ is 

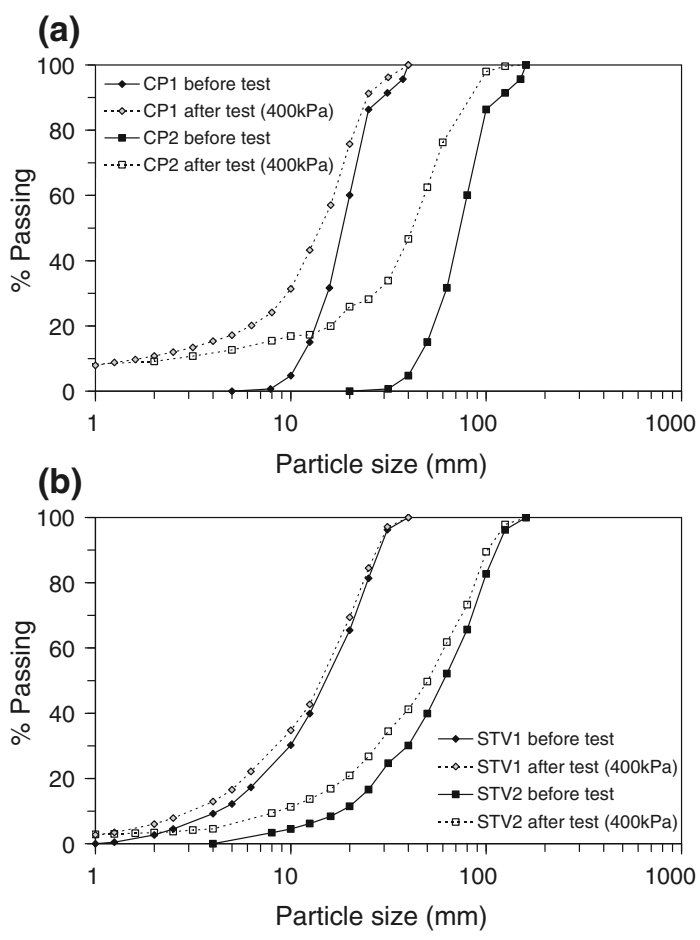

Fig. 11 Initial and final GSD of homothetic materials

Table 3 Large triaxial tests

\begin{tabular}{|c|c|c|c|}
\hline Material & $d_{\max }(\mathrm{mm})$ & $\sigma_{3}(\mathrm{kPa})$ & Initial void ratio \\
\hline \multicolumn{4}{|c|}{ Calcareous rockfill from Prefontaines $(\mathrm{CP})$} \\
\hline \multirow[t]{3}{*}{$\mathrm{CP} 1$} & 40 & 100 & 0.84 \\
\hline & & 200 & 0.83 \\
\hline & & 400 & 0.85 \\
\hline \multirow[t]{2}{*}{$\mathrm{CP} 2$} & 160 & 200 & 0.89 \\
\hline & & 400 & 0.86 \\
\hline \multicolumn{4}{|c|}{ Quartzite shale rockfill from Trois Vallées (STV) } \\
\hline \multirow[t]{4}{*}{ STV1 } & 40 & 100 & 0.49 \\
\hline & & 200 & 0.53 \\
\hline & & 300 & 0.54 \\
\hline & & 400 & 0.55 \\
\hline \multirow[t]{3}{*}{ STV2 } & 160 & 200 & 0.51 \\
\hline & & 300 & 0.53 \\
\hline & & 400 & 0.53 \\
\hline
\end{tabular}

made of a $2 \mathrm{~m}$ high double wall chamber. During the test preparation, both outer and inner volumes were filled simultaneously with water, maintaining the same pressure in both chambers. Therefore, the inner cylinder remains nondeformable during the test, and the volume change in the compartment is due only to volumetric deformation of the specimen and penetration of the loading piston. An exhaustive description of both triaxial devices and testing methodology can be found in $\mathrm{Hu}$ et al. [17]. Figure 12 presents a general scheme of the larger device, and Fig. 13 shows a general picture of both devices.

For dry samples preparation, materials were compacted by vibration in several layers and the average initial void ratios were equal to $0.85 \pm 0.03$ for $\mathrm{CP}$ and $0.53 \pm 0.04$ for STV. Figure 14 shows the mechanical response during drained triaxial testing for $\sigma_{3}^{\prime}$ between 100 and $400 \mathrm{kPa}$. Figure 11 shows the GSD before and after the test at $\sigma_{3}^{\prime}=400 \mathrm{kPa}$ for both materials. In Fig. 15, it can be seen that size affects both rockfills, with (a) a higher breakage ratio and (b) a slightly lower maximum friction angle for the coarser materials. For the breakage ratio, the definition proposed by Marsal [25] was used, given by the sum of positive differences between the percentage of the total sample contained in each size fraction before and after the test. The results 

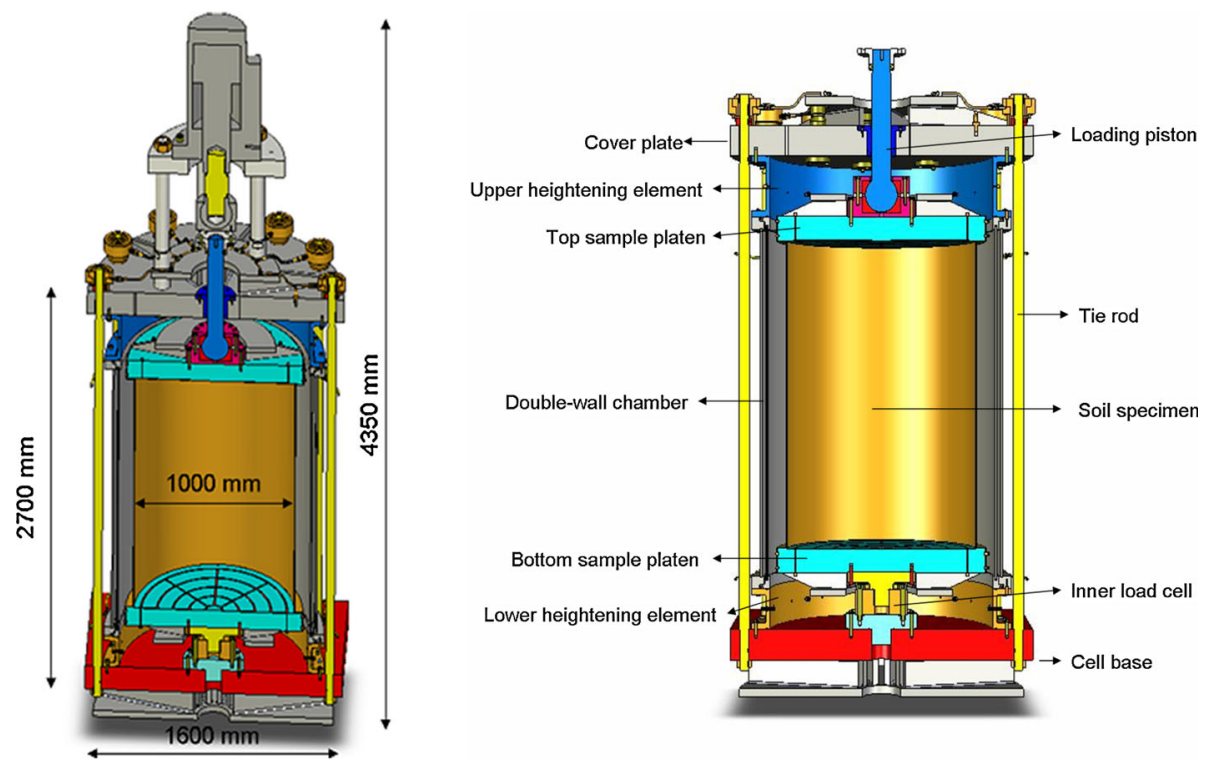

Fig. 12 Configuration of the large triaxial device [17]

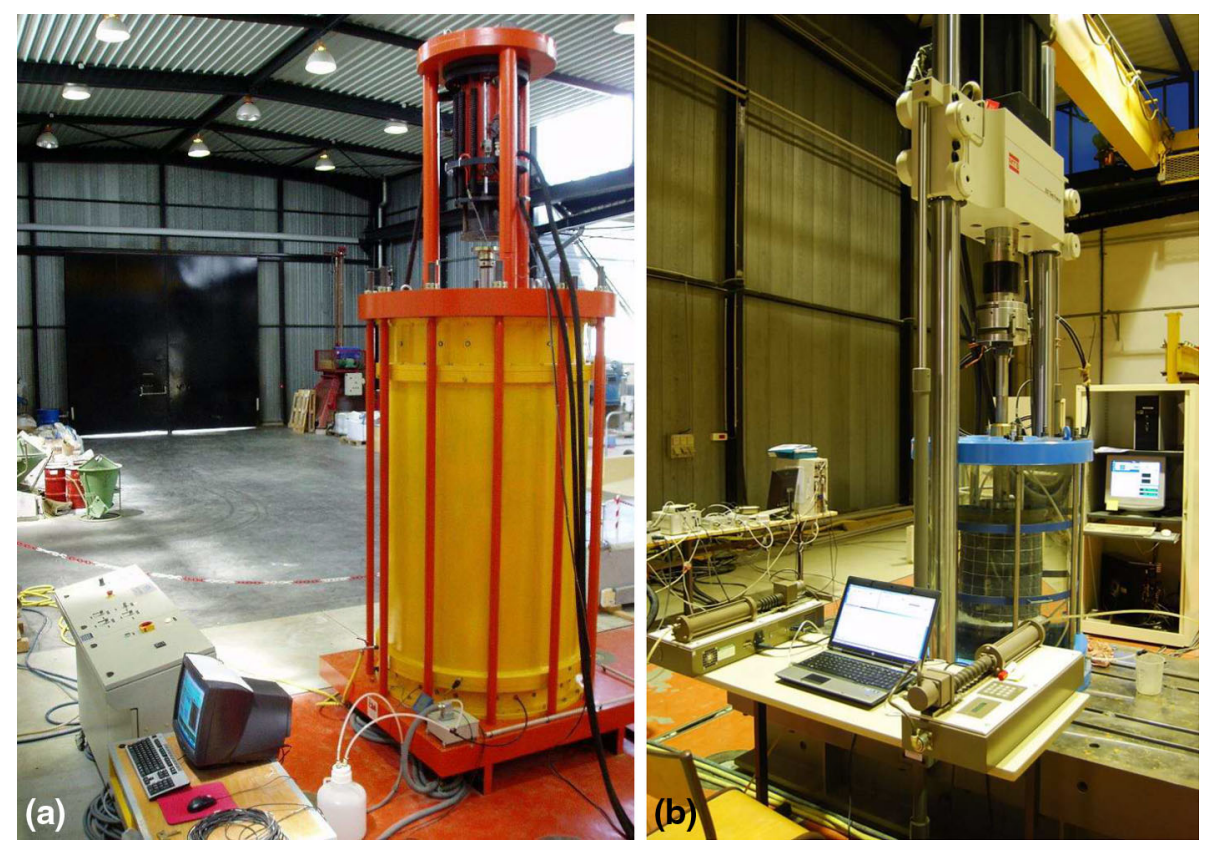

Fig. 13 Large triaxial devices at the Ecole Centrale Nantes laboratory: a 1,000 mm diameter and 2,000 kN of max. vertical load; b $250 \mathrm{~mm}$ diameter and $500 \mathrm{kN}$ of max. vertical load

in Fig. 15 are consistent with the size effect on the single particle crushing strength in Fig. 9. Nevertheless, as shown in Fig. 14, no strong size effect takes place in the volume changes, and probably small differences may be attributed to experimental data scatter. Marachi et al. [24] and Becker et al. [5] showed similar results when comparing two rockfills of homothetic GSD and with $d_{\max }$ of 50 and $150 \mathrm{~mm}$ (Pyramid Dam material rockfill, crushed basalt, Oroville Dam rockfill, sandstone). A possible explanation for these systematic results could be given by the relatively high ratio between $d_{\max }$ and the rockfill specimen diameter $D_{\text {sample }}$ (around $d_{\max } / D_{\text {sample }}=1 / 6$ ). Then, after a test to $20 \%$ axial strain, coarse particles could not displace themselves enough in order to dislocate after breakage and to allow for more contraction. Thus, full packing rearrangement may not be allowed under these conditions, and this could be of course more likely with a limited aspect ratio 

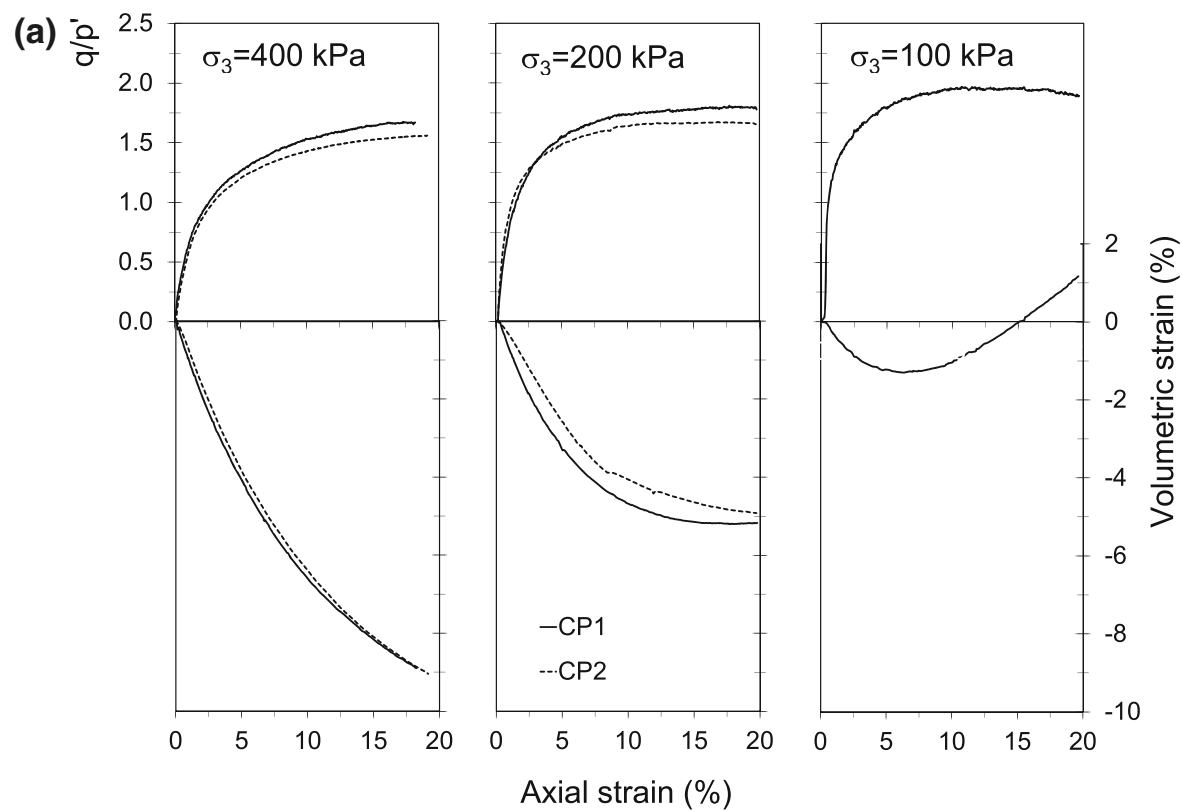

(b)
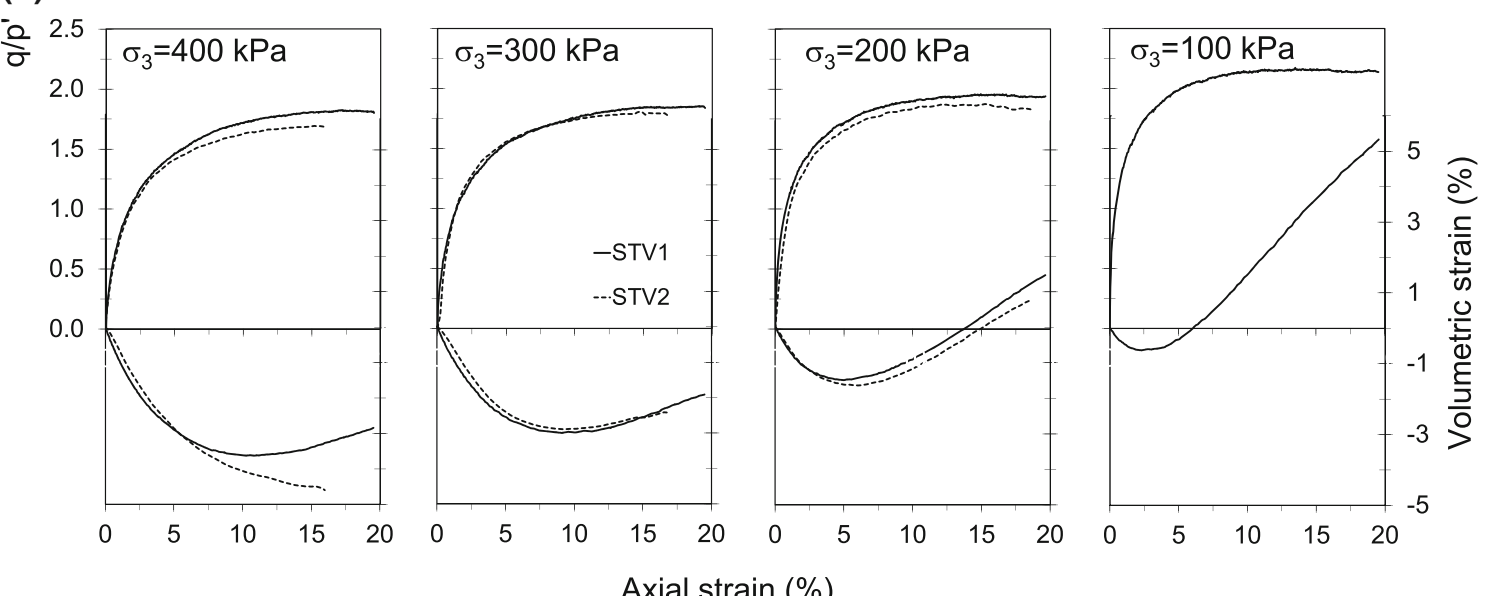

Axial strain (\%)

Fig. 14 Stress-strain curves for a CP and b STV rockfills

for cylindrical samples, as the results presented in this paper (i.e., 1.5/1). In fact, many broken coarse particles observed after the triaxial tests seem to stand without fragment dislodgment. In other words, some coarse grains actually broke but kept almost the same initial volume because all fragmented pieces stayed together forming the original particle shape, without enough relative displacement. Moreover, some of these grains were easily entirely recovered after the test, as shown in Fig. 16. Consequently, according to the results presented here, as well as the evidence from similar tests on rockfills, it is believed that the proposed testing methodology is not appropriate for size effects assessment on the material compressibility due to grain crushing.

According to published experimental results of shear tests on sand and glass beads where no crushing occurred $[14,21]$, as well as numerical simulations of uncrushable granular materials using the discrete element method [21,30,37], the critical state friction angle (i.e., constant shear at constant volume when shear strain increases) is not affected by the GSD, provided that the shape of the grains remains unchanged. Moreover, in crushable materials, it has also been shown that the critical friction angle does not depend on the breakage ratio [10,23]-i.e., for samples tested at different confining pressures and/or different straining. Therefore, it could be expected that its value is neither affected by size effects caused by particle crushing. Nevertheless, in our tests, the samples did not reach a pure critical state, and, in order to study size effects on the mobilized shear resistance, we focused our analysis on the shear strength envelope obtained from the maximum friction angle in each test. 

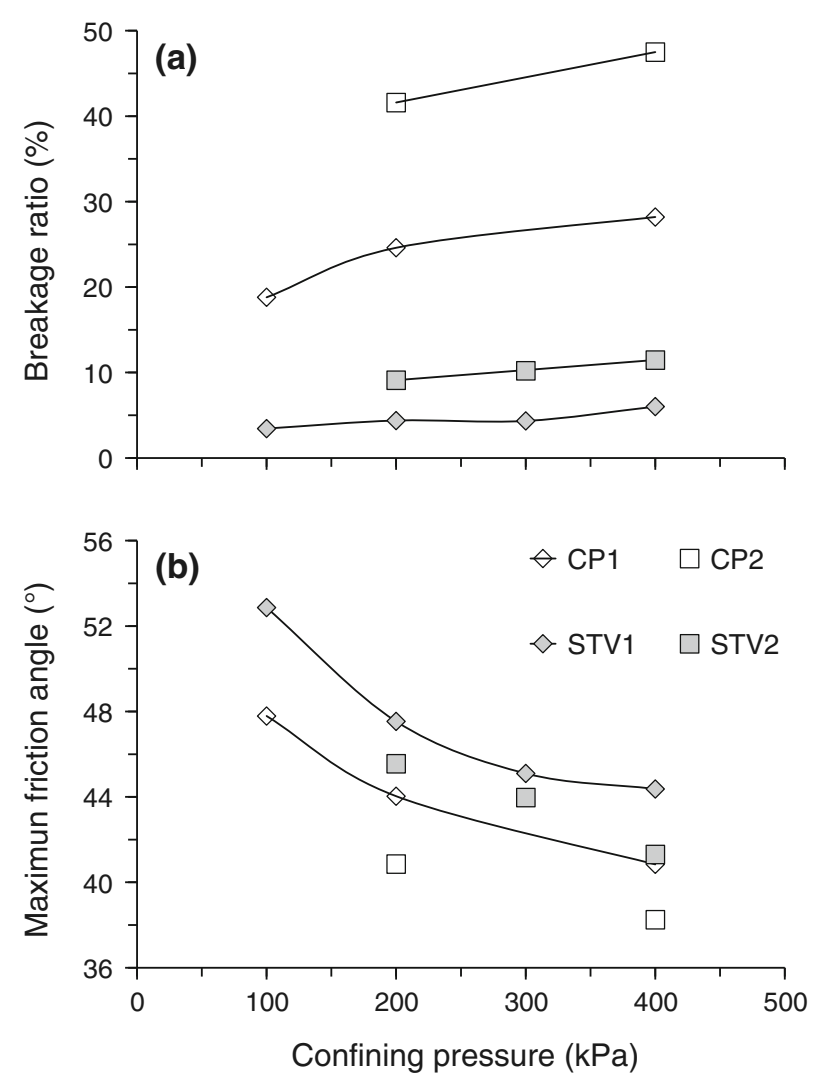

Fig. 15 Triaxial results: a breakage ratio and $\mathbf{b}$ maximum friction angles of CP and STV rockfills
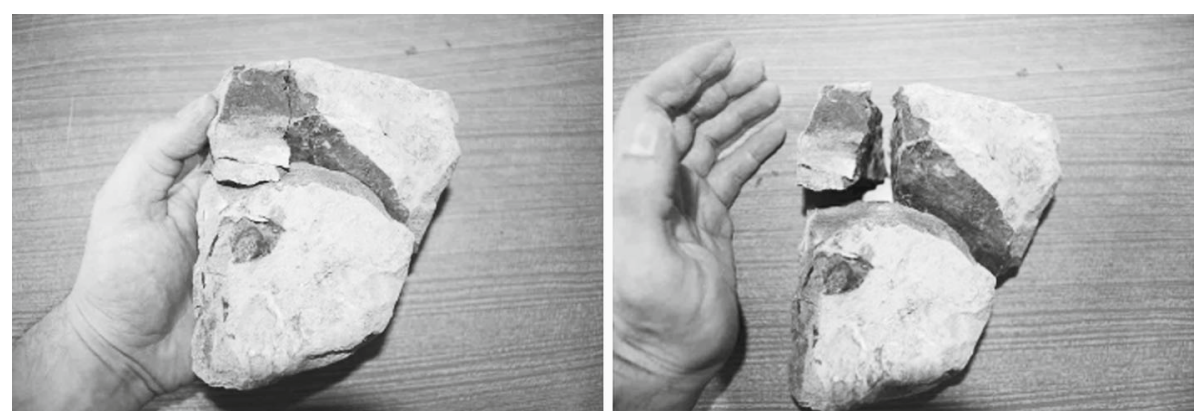

Fig. 16 Coarse grain of STV crushed after a triaxial test

\subsection{Size effect on shear envelopes and on stability of rockfill slopes}

Figure 17 shows the shear strength envelopes for CP, STV and rockfill materials tested by Marsal [26], which are made of the grains shown in Fig. 10 for the particle crushing strength. For comparison with the results presented in this paper, only the stress domain corresponding to the CP and STV triaxial tests has been analyzed, even if in most of Marsal's results the normal stresses vary up to $4 \mathrm{MPa}$. It can be seen that the CP is on the lower shear strength range, as well as Mica granitic gneiss rockfills. This is coherent with the particle crushing strength values from Fig. 10, where it is shown that those materials have the weakest particle strength. In the same way, STV is among the strongest rockfills in Fig. 17, consistently with its relatively high particle strength. However, this link between particle strength and the granular assembly strength envelope has to be considered with some caution, because of the influence of gradation and particle shape, so conclusions cannot be drawn by simply considering particle strength. 


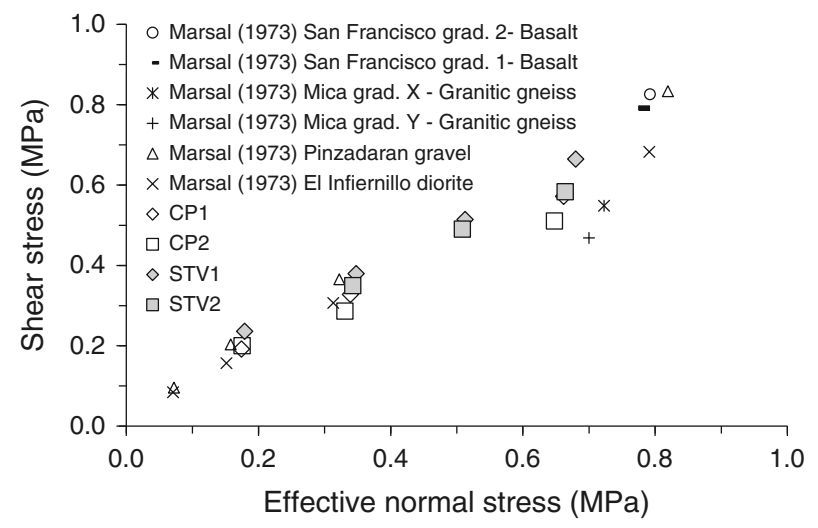

Fig. 17 Shear strength envelopes of Marsal's [26] tests, as well as CP and STV rockfills
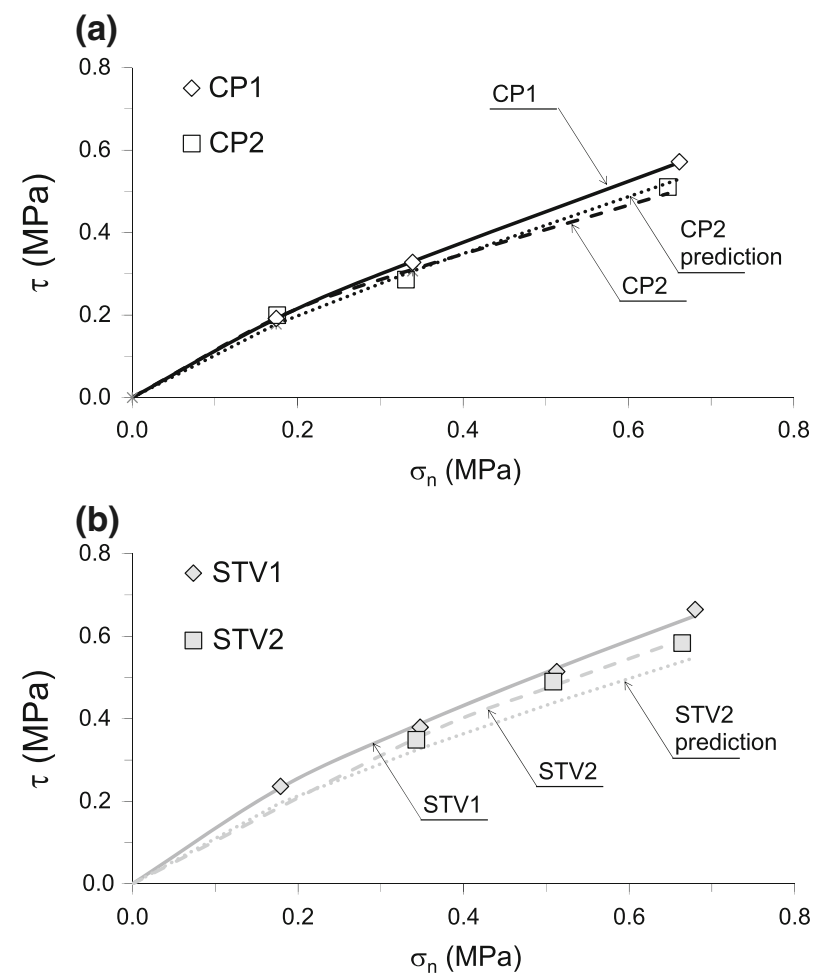

Fig. 18 Size effect predictions on the shear strength envelope of a CP and $\mathbf{b}$ STV rockfills

The shear envelopes of CP and STV were fitted to the expression suggested by De Mello [11] for a nonlinear envelope in rockfills:

$$
\tau=A\left(\sigma_{n}\right)^{b}
$$

where $A$ and $b$ are empirical parameters, $\tau$ is the rockfill shear strength, and $\sigma_{n}$ is the normal stress. Table 4 presents the best fitting of $A$ and $b$ for CP and STV, and Fig. 18 shows the experimental shear envelopes, as well as the fitted curve envelopes according to Eq. (8). Following Charles and Soares [8], the FS for the limit equilibrium slope stability based on the method of Bishop [7] can be expressed as

$$
\mathrm{FS}=\frac{A \Gamma(b, \beta)}{(\gamma H)^{(1-b)}}
$$

where $H$ is the height of the slope, $\gamma$ is the bulk density of the compacted rockfill and $\Gamma$ is the dimensionless stability number-depending on the slope inclination $(\beta)$ and $b$. Equation 9 assumes a strong bedrock founda- 


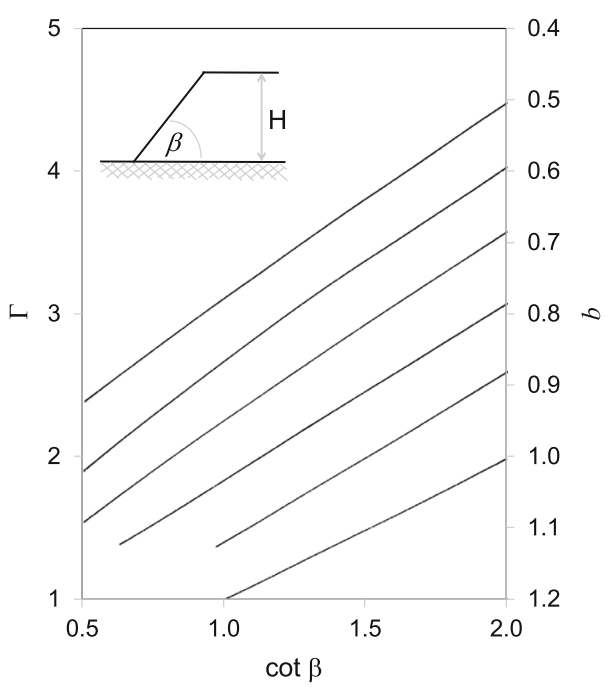

Fig. 19 Dimensionless stability numbers $\Gamma$ from circular slope failures [8]

Table 4 Summary of parameters for the prediction of Frossard's method

\begin{tabular}{lllll}
\hline Parameter & \multicolumn{2}{l}{ Material } & & STV1 \\
\cline { 2 - 4 } & CP1 & CP2 & STV2 \\
\hline$A$ & 0.80 & 0.68 & 0.87 & 0.81 \\
$b$ & 0.82 & 0.72 & 0.77 & 0.78 \\
$d_{\max }(\mathrm{mm})$ & 40 & 160 & 40 & 160 \\
$m_{\text {avg }}$ & 2.18 & & 1.54 & \\
$n_{d}$ & 0.63 & & 0.81 & \\
\hline
\end{tabular}

tion and a circular failure through the rockfill mass. For different material parameters and slope configurations, Charles and Soares [8] produced the chart in Fig. 19, which gives $\Gamma$ values for slope stability assessment. Then, if one considers two rockfill slopes, each one built with different materials $G 1$ and $G 2$, with heights $H_{1}$ and $H_{2}$ and considering shear envelopes characterized by empirical parameters $A_{G 1}-b_{G 1}$ and $A_{G 2}-b_{G 2}$, respectively, the FS ratio between $G 2$ and $G 1$ is given by

$$
\frac{\mathrm{FS}_{G 2}}{\mathrm{FS}_{G 1}}=\frac{\left(\gamma_{2} H_{2}\right)^{b_{2}-1}}{\left(\gamma_{1} H_{1}\right)^{b_{1}-1}} \cdot\left(\frac{A_{G 2}}{A_{G 1}}\right) \cdot\left(\frac{\Gamma_{G 2}\left(b_{G 2}, \beta\right)}{\Gamma_{G 1}\left(b_{G 1}, \beta\right)}\right) .
$$

Therefore, using rockfill slopes with the same geometry but composed by size scaled rockfills, Eq. (10) can be used to compare the impact on the FS due to shear strength reduction with the increase in particle size. For instance, considering arbitrary geometrical parameters $\tan \beta=1 / 1.5$ and $H_{2}=H_{1}=20 \mathrm{~m}$, a constant density for size scaled samples $\gamma_{1}=\gamma_{2}$ (average values were $\gamma=14.3$ and $17.8 \mathrm{kN} / \mathrm{m}^{3}$ for CP and STV, respectively) and fitted parameters $A$ and $b$ (see Table 4), the FS reduction between a fill built with CP1 compared to CP2 is about $30 \%\left(\mathrm{FS}_{\mathrm{CP} 2} / \mathrm{FS}_{\mathrm{CP} 1}=0.69\right)$. Likewise, for $\mathrm{STV}$, the difference is negligible $\left(\mathrm{FS}_{\mathrm{STV} 2} / \mathrm{FS}_{\mathrm{STV} 1}=0.99\right)$.

Nevertheless, this simplified hypothetical analysis does not necessarily reveal the case occurring in fullscale rockfill slopes. As shown in Fig. 10, CP is a relatively weak rock, and normally in the field such a material is not used for embankments construction. Moreover, the material is very vulnerable to grain crushing because its initial GSD is quite uniform [16], which is generally not the case in real projects, where the use of well-graded materials is preferred in order to reach high in situ densities. However, rockfills in real civil works can be easily of one order of magnitude coarser than the size scaled materials tested in this work. Hence, size effects could be nonnegligible and should be taken into account. Then, extrapolated results from predictive methods (validated with experimental data) are suitable in the design procedures. 


\subsection{Validation of a theoretical predictive method}

The predictive method proposed by Frossard [12] considers two homothetic granular materials (e.g., $G 1$ the finer and $G 2$ the coarser) under the same loading condition and with the same mineralogy and grain shape. Thus, if an identical survival probability is assumed for two grains under compression of characteristic sizes $d_{1}$ and $d_{2}$ in $G 1$ and $G 2$, respectively, the following relation for the particle crushing strength $\left(\sigma_{G i}\right)$ can be obtained from Eq. (3):

$$
\sigma_{G 2}=\sigma_{G 1}\left(\frac{d_{2}}{d_{1}}\right)^{-n_{d} / m}
$$

Then, according to Eq. (1), crushing forces of each particle $\left(f_{G i}\right)$ are related by

$$
f_{G 2}=f_{G 1}\left(\frac{d_{2}}{d_{1}}\right)^{2-n_{d} / m}
$$

Under the same stress condition, it has been shown in this paper that the amount of particle breakage will be higher in $G 2$, compared to $G 1$, since coarse grains have lower strength. Frossard's method is based on the assumption that the breakage ratio is the same in both materials, which is possible only if the stress magnitude on $G 2$ is lower. Then, focusing on contact micromechanics and based on Eq. (12), a condition for the intensity of the contact forces between grains $n$ and $p\left(f_{(n / p)}\right)$ is obtained:

$$
f_{G 2(n / p)}=f_{G 1(n / p)}\left(\frac{d_{2}}{d_{1}}\right)^{2-n_{d} / m} .
$$

In parallel, the geometric scaling gives a relationship between branch vectors $\left(l_{(n / p)}\right)$ and grain volumes:

$$
l_{G 2(n / p)}=l_{G 1(n / p)}\left(\frac{d_{2}}{d_{1}}\right) \text { and } V_{G 2}=V_{G 1}\left(\frac{d_{2}}{d_{1}}\right)^{3} .
$$

The stress tensors $\sigma_{i j}$ for $G 2$ and $G 1$ are given by the following expressions [9,35]:

$$
\sigma_{i j-G 1}=\frac{1}{V_{G 1}} \sum_{n<p \leq N} f_{G 1(n / p)} \otimes l_{G 1(n / p)} \quad \text { and } \quad \sigma_{i j-G 2}=\frac{1}{V_{G 2}} \sum_{n<p \leq N} f_{G 2(n / p)} \otimes l_{G 2(n / p)} .
$$

Hence, combining Eqs. (13), (14) and (15), the stress tensor of $G 2$ as a function of $G 1$ is obtained:

$$
\sigma_{i j-G 2}=\left(\frac{d_{2}}{d_{1}}\right)^{-n_{d} / m} \frac{1}{V_{G 1}} \sum_{n<p \leq N} f_{G 1(n / p)} \otimes l_{G 1(n / p)} .
$$

Therefore, in order to obtain the same breakage ratio in each granular material under shearing, the reduction factor $\left(d_{2} / d_{1}\right)^{-n d / m}$ should be applied to the shear envelope $\left(\tau-\sigma_{n}\right)$ for the granular assembly:

$$
\tau_{G 2}=\tau_{G 1}\left(\frac{d_{2}}{d_{1}}\right)^{-n_{d} / m} \text { and } \sigma_{n-G 2}=\sigma_{n-G 1}\left(\frac{d_{2}}{d_{1}}\right)^{-n_{d} / m}
$$

Finally, considering the curved failure envelope in Eq. (8) for $G 1$, with fitted parameters $A_{G 1}$ and $b_{G 1}$, a shear strength envelope can be predicted for $G 2$ :

$$
\tau_{G 2}=A_{G 1} \cdot\left(\frac{d_{2}}{d_{1}}\right)^{\frac{-n_{d}\left(1-b_{G 1}\right)}{m}} \cdot\left(\sigma_{n-G 2}\right)^{b_{G 1}}
$$

In this paper, the statistical data on rock aggregate crushing strength of CP and STV have been used in order to validate the prediction of Eq. (18). Table 4 presents the set of parameters used, and Fig. 18a, b shows the predicted envelopes for CP2 and STV2, respectively. It can be seen that Frossard's method reasonably predicts the size effects for both rockfills, even if it appears to fall on the safe side for STV. This could be explained because the method does take into account neither the magnitude of particle strength nor the effect of the initial GSD. It is well known that these material properties strongly affect the amount of grain breakage, which is amplified with relatively weak grains [6] and rather uniform GSD [16]. In the case of STV, it has been shown that it is composed of relatively strong grains and a well-graded GSD, if compared to CP. Then, for an equivalent shear state, STV presents a lower breakage ratio (see Fig. 15a) and therefore a less marked size effect on the shear envelope. 


\section{Conclusions}

As with any brittle material, the experimental evidence shows that there is a size effect on the crushing strength of rock aggregates, expressed as an inverse relation between size and strength. These results on rock aggregates can explain the size effects in crushable granular packings, such as rockfills. However, due to the necessity of large and costly experimental equipments, the data available on size scaling of the mechanical behavior of coarse granular materials are still quite scarce.

In this paper, new data on rock aggregates tensile strength and on the mechanical behavior of size scaled rockfills are presented. First, the size effect on particle strength has been tested for rock aggregates of a porous limestone and an anisotropic shale rock. The suitability of Weibull's theory in order to fit the experimental results on the crushing strength has been evaluated. As reported in the literature, the theory assumes a bulk tensile failure within homogeneous samples. Nevertheless, rockfills are composed by grinded aggregates which are randomly shaped (normally angular or subangular), and the rock could have quite heterogeneous structure. Even if under these conditions the hypothesis of Weibull's theory may not be satisfied, the statistical distribution can be fitted to experimental results and can be used as a purely phenomenological statistical tool for size effects.

Second, the experimental results on large triaxial tests showed that when grain shape and mineralogy are preserved between two granular materials with size scaled GSD (maximum particle sizes of 40 and $160 \mathrm{~mm}$ ), size effects are observed as an increase in the amount of particle breakage and a slight decrease in the shear strength envelope for the coarser material. Quantitatively, for a particle size reduction factor of 4 , a decrease in the maximum friction angle of about $2^{\circ}$ to $3^{\circ}$ was obtained. On the other hand, no size effect in the material compressibility has been observed in large triaxial tests, presumably due to a limited straining, which does not allow for full packing rearrangement after crushing.

Size effects on shear strength of rockfills seem to be limited in the laboratory. However, they could be more significant in full-scale materials, which can easily have particles sized around one order of magnitude coarser than the largest one in a large laboratory sample. Therefore, predictive methods are needed in order to take into account size effects in engineering designs. In this work, the experimental results were used for validation of the only existing theoretical method that links the rock aggregate with the strength of the granular assembly, obtaining a good agreement. However, the method makes this link based only on the size effect on particle strength, without considering other materials properties that affect grain breakage. Consequently, when the amount of breakage is relatively low, the method gives a conservative (safe) prediction.

Further work may be done on the influence of particle shape and the mineralogy of rock aggregates. These properties could change along size fractions due to the geological morphology of the rock, adding more uncertainties to size effect predictions. Thus, a representative scaled sample may not always be obtained by simply sieving and dividing a granular material by particle sizes, but also by considering the size-dependent geological composition and angularity of rock aggregates.

Acknowledgments This work was part of the French research project ECHO (size effects in Civil Engineering Granular Fill Works), sponsored by the French National Agency for Research (ANR) and involving a wide partnership, including: EIFFAGE Travaux Publics; Electricité de France-CIH, Laboratoire de Mécanique des Solides from Ecole Polytechnique, Centre d'Etudes Techniques de l'Equipement-Laboratoire Régional des Ponts et Chaussées Lyon, Coyne et Bellier Ingénieurs-Conseils (now incorporated in Tractebel Engineering), Institut de Recherche en Génie Civil et Mécanique from Ecole Centrale Nantes. Carlos Ovalle gratefully acknowledges the financial support of CONICYT Chile, the Embassy of France in Chile and Pontificia Universidad Católica de Chile. The authors would like to thank the anonymous reviewers for their valuable comments and suggestions to improve the quality of the paper.

\section{References}

1. Alonso, E.E., Tapias, M., Gili, J.: Scale effects in rockfill behaviour. Géotech. Lett. 2, 155-160 (2012)

2. Bard, E., Anabalon, M., Campana, J.: Waste rock behavior at high pressures: dimensioning high waste rock dumps. In: Hicher, P-.Y. (ed.) Multiscale Geomechanics: From Soil to Engineering Projects, pp. 86-112. ISTE/Wiley, ISBN 978-1-84821-246-6 (2012)

3. Bažant, Z.P., Planas, J.: Fracture and Size Effect in Concrete and Other Quasibrittle Materials. CRC Press, USA (1998)

4. Bažant, Z.P., Xi, Y., Reid, S.G.: Statistical size effect in quasi-brittle structures-Part 1: Is Weibull theory applicable? J. Eng. Mech. ASCE 117, 2609-2622 (1991)

5. Becker, E., Chan, C. K., Seed, H.B.: Strength and deformation characteristics of rockfill materials in plane strain and triaxial compression tests. Report No. TE-72-3 (1972)

6. Billam, J.: Some aspects of the behaviour of granular materials at high pressures. Proceedings of the ROSCOE Memorial Symposium, Cambridge, pp. 69-80 (1971) 
7. Bishop, A.W.: The use of the slip circle in the stability analysis of slopes. Géotechnique 5, 7-17 (1955)

8. Charles, J.A., Soares, M.M.: Stability of compacted rockfill slopes. Géotechnique 34, 61-70 (1984)

9. Christofferson, J., Mehrabadi, M.M., Nemat-Nassar, S.: A micromechanical description on granular material behavior. ASME J. Appl. Mech. 48, 339-344 (1981)

10. Coop, M.R., Sorensen, K.K., Bodas Freitas, T., Georgoutsos, G.: Particle breakage during shearing of a carbonate sand. Géotechnique 54, 157-163 (2004)

11. De Mello, V.F.B.: Reflections on design decisions of practical significance to embankment dams. Géotechnique 27, 281-355 (1977)

12. Frossard, E.: Scale effects in granular fill shear strength and in stability of large rockfill structures. XVIIth ICSMFE, Alexandria, Egypt, 5-9 Oct 2009

13. Frossard, E., Hu, W., Dano, C., Hicher, P.Y.: Rockfill shear strength evaluation: a rational method based on size effects. Géotechnique 62, 415-428 (2012)

14. Gang, L., Ovalle, C., Dano, C., Hicher. P-Y.: Influence of grain size distribution on critical states of granular materials. In: Yang et al., Q. (eds.) Constitutive Modeling of Geomaterials, pp. 207-210. Springer Series in Geomechanics and Geoengineering, Springer, Berlin (2013)

15. Griffith, A.A.: The phenomena of rupture and flow in solids. Phil. Trans. R. Soc. Lond. A 221, 163-198 (1921)

16. Hardin, B.O.: Crushing of soil particles. J. Geotech. Eng. ASCE 111, 1177-1192 (1985)

17. Hu, W., Dano, C., Hicher, P.-Y., Le Touzo, J.-Y., Derkx, F., Merliot, E.: Effect of sample size on the behavior of granular materials. Geotech. Test. J. 34, 186-197 (2011)

18. Jaeger, J.C.: Failure of rocks under tensile conditions. Int. J. Rock. Min. Sci. 4, 219-227 (1967)

19. Lee, D.M.: The angles of friction of granular fills. Ph.D. thesis. University of Cambridge (1992)

20. Lim, W.L., McDowell, G.R., Collop, A.C.: The application of Weibull statistics to the strength of railway ballast. Granul. Matter 6, 229-237 (2004)

21. Liu, Y.-J., Gang, L, Yin, Z.-Y., Dano, C., Hicher, P.-Y., Xia, X.-H., Wang, J.H.: Influence of grading on the undrained behavior of granular materials. Comptes Rendus Mécanique. (available online 31 December 2013) (2013, in press)

22. Lobo-Guerrero, S., Vallejo, L.: Application of Weibull statistics to the tensile strength of rock aggregates. J. Geotech. Geoenviron. 132, 786-790 (2006)

23. Luzzani, L., Coop, M.R.: On the relationship between particle breakage and the critical state of sands. Soils Found. 42, 71-82 (2002)

24. Marachi, N.D., Chan, C.K., Seed, H.B., Duncan, J.M.: Strength and deformation characteristics of rockfills materials. Report No. TE-69-5, Department of Civil Engineering, University of California, Berkeley (1969)

25. Marsal, R.: Large-scale testing of rockfill materials. J. Soil Mech. Found. Div. ASCE 93(SM2), $27-44$ (1967)

26. Marsal, R.: Mechanical properties of rockfill dams. In: Hirschfeld, R.y Poulos, S. (eds.) Embankment-dam Engineering: Casagrande Volumen, p. 454. Wiley, New York (1973)

27. McDowell, G.R.: On the yielding and plastic compression of sand. Soils Found. 42, 139-145 (2002)

28. McDowell, G.R., Amon, A.: The application of Weibull statistics to the fracture of soil particles. Soils Found. 40, $133-141(2000)$

29. McDowell, G.R., Bolton, M.D.: On the micromechanics of crushable aggregates. Géotechnique 48, 667-679 (1998)

30. Muir Wood, D., Maeda, K.: Changing grading of soil: effect on critical states. Acta Geotech. 3, 3-14 (2008)

31. Nakata, Y., Hyde, A.F.L., Hyodo, M., Murata, H.: A probabilistic approach to sand particle crushing in the triaxial test. Géotechnique 49, 567-583 (1999)

32. Nakata, Y., Kato, Y., Hyodo, M., Hyde, A.F.L., Murata H.: One-dimensional compression behaviour of uniformly graded sand related to single particle crushing strength. Soils Found. 41, 39-51 (2001)

33. Nobari, E., Duncan, J.: Effect of reservoir filling on stresses and movements in earth and rockfill dams, International Report No. TE-72-1, University of California, pp. 1-186 (1972)

34. Ratigan, J.L.: A statistical fracture mechanics approach to the strength of brittle rock. Ph.D. thesis, University of Berkeley (1981)

35. Rothenburg, L., Selvadurai, A.: Micromechanical definitions of the Cauchy stress tensor for particular media. In: Selvadurai, A. (ed.) Mechanics of Structured Media, pp. 469-486. Elsevier, Amsterdam (1981)

36. Verdugo, R., De la Hoz, K.: Strength and stiffness of coarse granular soils. Soil Stress-Strain Behavior: Measurement, Modeling and Analysis, Geotechnical Symposium in Roma, 16-17 March (2006)

37. Voivret, C., Radjaï, F., Delenne, J.-Y., El Youssoufi, M.S.: Multiscale force networks in highly polydisperse granular media. Phys. Rev. Lett. 102, 178001 (2009)

38. Weibull, W.: A statistical theory of the strength of materials. Proc. R. Swed. Inst. Eng. Res. 151 (1939) 